\title{
Analysis of sputum markers in the evaluation of lung inflammation and functional impairment in symptomatic smokers and COPD patients
}

\author{
Gregorino Paone ${ }^{\mathrm{a}, \mathrm{b}, *}$, Vittoria Conti ${ }^{\mathrm{c}}$, Annarita Vestri ${ }^{\mathrm{d}}$, Alvaro Leone ${ }^{\mathrm{e}}$, Giovanni Puglisi ${ }^{\mathrm{f}}$, \\ Fulvio Benassi ${ }^{\mathrm{f}}$, Giuseppe Brunetti ${ }^{\mathrm{f}}$, Giovanni Schmid ${ }^{\mathrm{b}}$, Ilio Cammarella ${ }^{\mathrm{g}}$ and Claudio Terzano ${ }^{\mathrm{c}}$ \\ ${ }^{a}$ Department of Cardiovascular and Respiratory Sciences, 'Sapienza' University of Rome, S.Camillo-Forlanini \\ Hospital, Rome, Italy \\ ${ }^{\mathrm{b}}$ IRCCS Fondazione Don Carlo Gnocchi-Onlus, Rome, Italy \\ ${ }^{\mathrm{c}}$ Department of Cardiovascular and Respiratory Sciences, Respiratory Diseases Unit, 'Sapienza' University of \\ Rome, Fondazione E. Lorillard Spencer Cenci, Rome, Italy \\ ${ }^{\mathrm{d}}$ Department of Public Health and Infectious Disease, 'Sapienza' University of Rome, Italy \\ e Pathology Unit, S.Camillo-Forlanini Hospital Hospital, Rome, Italy \\ ${ }^{\mathrm{f}} \mathrm{S}$. Camillo-Forlanini Hospital, Rome, Italy \\ 'Department 'Attilio Reali', 'Sapienza' University of Rome, Italy
}

\begin{abstract}
The pivotal role of neutrophils and macrophages in smoking-related lung inflammation and COPD development is well-established.

We aimed to assess whether sputum concentrations of Human Neutrophil Peptides (HNP), Neutrophil Elastase (NE), Interleukin8 (IL-8), and Metalloproteinase-9 (MMP-9), major products of neutrophils and macrophages, could be used to trace airway inflammation and progression towards pulmonary functional impairment characteristic of COPD.

Forty-two symptomatic smokers and 42 COPD patients underwent pulmonary function tests; sputum samples were collected at enrolment, and 6 months after smoking cessation.

HNP, NE, IL-8, MMP-9 levels were increased in individuals with COPD $(p<0.0001)$. HNP and NE concentrations were higher in patients with severe airways obstruction, as compared to patients with mild-to-moderate COPD $(p=0.002)$. A negative correlation was observed between FEV 1 and HNP, NE and IL-8 levels $(p<0.01)$, between FEV $1 / \mathrm{FVC}$ and HNP, NE and IL-8 levels $(p<0.01)$, and between NE enrolment levels and $\mathrm{FEV}_{1}$ decline after 2 years $(p=0.04)$.

ROC analysis, to discriminate symptomatic smokers and COPD patients, showed the following AUCs: for HNP 0.92; for NE 0.81; for IL-8 0.89; for MMP-9 0.81; for HNP, IL-8 and MMP-9 considered together 0.981.

The data suggest that the measurement of sputum markers may have an important role in clinical practice for monitoring COPD. Keywords: Airway inflammation, Chronic obstructive pulmonary disease, neutrophil elastase, human neutrophil peptides, interleukin-8, likelihood ratio, metalloproteinase-9, sputum, receiver operating characteristic analysis, smoking
\end{abstract}

\section{List of abbreviations}

$\alpha 1$-AT: $\quad \alpha 1$-antitrypsin

AUC: $\quad$ area under the curve
BAL: $\quad$ bronchoalveolar lavage

CO: $\quad$ carbon monoxide

COPD: $\quad$ Chronic Obstructive Pulmonary Disease

DTT: Dithiothreitol

ECP: $\quad$ Eosinophilic-Cationic Protein

FEV1: $\quad$ Forced Expired Volume in one second

FEV1/FVC: FEV1 expressed as a percentage of FVC

HBSS: Hank's Buffered Salt Solution

HNP: $\quad$ Human Neutrophil Peptides
Cardiovascular and Respiratory Sciences, University "La Sapienza", S.Camillo-Forlanini Hospital, Via Portuense 332, 00149 Rome, Italy. Tel./Fax: +39 06 55552553; E-mail: rpaone1023@yahoo.com. 

IL-8: Interleukin-8
MMPs: Matrix Metalloproteinases
MMP-9: Metalloproteinase-9
NE: $\quad$ Neutrophil Elastase
PFTs: Pulmonary Function Tests
ROC: receiver operating characteristics
$\mathrm{StcO}_{2}$ : Transcutaneous oxygen saturation
TIMPs: Tissue Inhibitors of Metalloproteinases

\section{Introduction}

Chronic Obstructive Pulmonary Disease (COPD) is an important cause of chronic morbidity and mortality throughout the world, and represents a major public health concern.

It is widely recognized that the prolonged exposure to harmful factors, such as cigarette smoke, induces a sustained inflammatory response all through the airways and lung parenchyma that accounts for the airway damage and remodelling, and lastly for the chronic airflow limitation characteristic of the disease [1,2]. The degree of this inflammatory response correlates with the grade of airways obstruction $[3,4]$ and with the prognosis of COPD patients [5].

COPD is a complex disease with multiple pathological components, which may tend to be underestimated when spirometry is used as the only approach to evaluate the disorder. Additional measures are needed to obtain a more complete and clinically relevant assessment of COPD [6]. This may enable a better definition of the different clinical phenotypes of the disease and help to improve the evaluation of disease activity and efficacy of therapy.

With this in mind, it is pivotal to identify molecules which may act as markers for detection and monitoring of smoking-related inflammation.

The role of neutrophils and macrophages in smokingrelated lung inflammation and COPD development is well-established [7].

These cells release a variety of pro-inflammatory molecules that contribute to the lung destruction and remodelling, which follow smoking exposure.

In the present study we aimed to assess whether the sputum concentrations of Human Neutrophil Peptides (HNP), Interleukin-8 (IL-8), Neutrophil Elastase (NE), and Matrix Metalloproteinase-9 (MMP-9), major products derived from alveolar macrophages and neutrophils, could be used, considered as a single marker or as a panel, in symptomatic smokers and patients with COPD, as indicators of airway inflammation and progression towards pulmonary functional impairment, and could be correlated with the degree of airways obstruction.

In addition, in order to investigate the effect of smoking cessation on airway inflammation, we organized a smoking cessation program and collected sputum samples from the subjects who quitted smoking.

\section{Patients and methods}

\subsection{Patients}

A consecutive population of current smokers with and without COPD (according to the Global Initiative for Chronic Obstructive Lung Disease, GOLD, guidelines [1]) was referred to our smoking cessation centre or underwent pulmonary function tests for respiratory symptoms. Inclusion criteria were: age more than 18 years, a smoking habit of 10 or more cigarettes per day for at least 2 years, no atopy and no respiratory tract infection 30 days prior to the study.

To avoid a potential underestimation of the difference in markers' concentrations between subjects with and without COPD, we excluded from evaluation individuals receiving inhaled and/or oral corticosteroids in the 6 months prior the study [8-10].

Subjects included in the study were stratified in 2 groups: 1) symptomatic smokers, subjects with chronic respiratory symptoms (i.e. chronic cough and sputum production) without airway obstruction; 2) COPD patients having $\mathrm{FEV}_{1} / \mathrm{FVC}$ post-bronchodilator $<0.7$. According to GOLD guidelines [1], the severity of COPD was based on $\mathrm{FEV}_{1} \%$ predicted postbronchodilator: a) stage I, mild COPD, with a $\mathrm{FEV}_{1}>$ $80 \%$; b) stage II, moderate COPD, with $50 \% \leqslant$ FEV1 $<80 \%$; c) stage III, severe COPD, with $30 \% \leqslant \mathrm{FEV}_{1}$ $<50 \%$; d) stage IV, very severe COPD, $\mathrm{FEV}_{1}<30 \%$, or $30 \% \leqslant \mathrm{FEV}_{1}<50 \%$ plus chronic respiratory failure.

The Ethical Committee approved the study (protocol no. 584/CE), and all the participants agreed by signing the informed consent.

\subsection{Enrollment phase}

A complete smoking history, including smoking habits and number of cigarettes per day was recorded.

Baseline spirometric measurements (Quark PFT Cosmed, Pavona, Italy) were performed by experienced personnel following the American Thoracic Society and European Respiratory Society recommendations and the reference values were those approved by the 
European Respiratory Society [11]. Bronchodilator responsiveness to $400 \mu \mathrm{g}$ salbutamol was measured and post-bronchodilator values were used [1].

Transcutaneous oxygen saturation $\left(\mathrm{StcO}_{2}\right)$ was measured by a pulse oximeter (Respironics, Marietta GA, USA).

All individuals underwent an identical smoking cessation intervention and received behavioural counselling with or without a specific pharmacological treatment.

\subsection{Sputum processing and analyses}

Spontaneous sputum samples were collected at the enrolment evaluation, and 6 months after smoking cessation from the subjects who quitted smoking.

Samples were processed within 120 minutes according to literature; briefly, sputum was incubated for 15 minutes with 4 times its weight of $0.01 \mathrm{M}$ dithiothreitol (DTT) in Hank's Buffered Salt Solution (HBSS). After incubation the volume of HBSS was doubled and incubated for 5 more minutes. The suspension was then filtered through a $50 \mu \mathrm{m}$ nylon gauze to remove mucus and debris and centrifuged at $2000 \mathrm{rpm}$ for 10 minutes. Total cell counts was performed manually by using an haemocytometer determining cell viability by the trypan blue exclusion method. Sputum samples adequacy was evaluated following current literature [10,12-14].

Supernatants were frozen at $-80^{\circ} \mathrm{C}$ until protein quantification assays were performed, then they were thawed, and sputum HNP, IL-8, MMP-9, and NE concentrations were quantified by using commercial sandwich ELISA following manufacturer instructions (Cell Sciences, Canton MA, R \&D Minneapolis MN, Hbt Canton MA).

\subsection{Follow-up}

Current smoking status was investigated weekly during behavioural counselling. After the three month treatment phase, participants were evaluated monthly in order to provide a 6 month analysis period. Selfassessed smoking cessation was validated by measuring carbon monoxide concentration in expired air and was confirmed by telephone interviews with household members. Sustained quitters were defined as participants whose self-assessed continuous smoking cessation, at each evaluation, was validated by carbon monoxide (CO) concentration in exhaled air $\leqslant 10 \mathrm{ppm}$ and by confirmation from a household member.
Current smokers were considered individuals who admitted smoking and/or whose exhaled CO levels were $>10 \mathrm{ppm}$ [15].

After 2 years from enrolment evaluation, participants were invited to attend pulmonary function tests (PFTs) with the aim to investigate a potential correlation between baseline markers levels and pulmonary functional decline.

\subsection{Statistical analysis}

The calculation of sample size was based on preliminary data for HNP and on previous reports for NE, MMP9 and IL8 [4,9,16-18]. For the HNP group, sample sizes of 38 and 38 achieved $90 \%$ power to detect a difference of -1.8 between the null hypothesis that both group means were 2.0 and the alternative hypothesis that the mean of group 2 was 3.8 with estimated group standard deviations of 2.4 with a significance level (alpha) of 0.05 using a two-sided two-sample ttest. To ensure an adequate sample, we aimed to enrol 42 subjects in each group (to overcome a possible $10 \%$ rate of not evaluable sputum samples). For NE, IL-8, and MMP9 the differences reported in the literature between symptomatic smokers and COPD were so wide to require much smaller samples sizes as compared to those estimated for HNP.

Continuous data are shown as mean \pm standard deviation and as median (range). Differences between groups were analyzed using the Mann Whitney U test. In the group of individuals who successfully quitted smoking, differences in markers sputum concentrations at baseline and after 6 months were analyzed by the Wilcoxon signed-rank test.

Correlation coefficients between variables were determined by the Spearman's rank correlation analysis.

We calculated sensitivity, specificity, likelihood ratios and their confidence intervals.

We performed the receiving operating characteristics (ROC) curve, which was constructed by plotting sensitivity on the $\mathrm{y}$-axis and 1 - specificity on the $\mathrm{x}$-axis, for all possible cut-off values of a clinical test.

Measures were combined through logistic regression. The best model was selected as the model minimizing the Akaike Information Criterion (AIC), among $2^{4}$ possible models. The resulting combined scores were formed by multiplying the diagnostic measures included in the best model by the maximum likelihood estimates of their corresponding estimated log-odds, and summing the three addends. Values of $p<0.05$ were considered significant. 
Table 1

Baseline characteristics

\begin{tabular}{lcccc}
\hline & Symptomatic smokers $(n=42)$ & COPD $(n=42)$ & p value & Total $(n=84)$ \\
\hline Age (years) & $53.00 \pm 13.41$ & $58.74 \pm 15.16$ & 0.082 & $55.87 \pm 14.52$ \\
Cigarette/day & $25.07 \pm 14.65$ & $25.76 \pm 14.57$ & 0.696 & $25.42 \pm 14.53$ \\
Years of smoking & $26.83 \pm 11.35$ & $31.26 \pm 12.94$ & 0.134 & $29.05 \pm 12.30$ \\
Pack-years & $36.29 \pm 31.42$ & $41.88 \pm 31.57$ & 0.230 & $39.08 \pm 31.43$ \\
FEV $\%$ of predicted & $82.83 \pm 1.82$ & $55.84 \pm 18.05$ & $<0.0001$ & $69.34 \pm 20.65$ \\
FEV/FVC $(\%)$ & $85.17 \pm 7.98$ & $57.97 \pm 10.42$ & $<0.0001$ & $71.57 \pm 16.50$ \\
$\mathrm{StcO}_{2}(\%)$ & $97.4 \pm 1.2$ & $93.9 \pm 1.1$ & $<0.0001$ & $95.7 \pm 1.3$ \\
\hline
\end{tabular}

Values are expressed as mean \pm Standard Deviation;

$\mathrm{FEV}_{1}=$ Forced Expired Volume in one second; $\mathrm{FEV}_{1} / \mathrm{FVC}=\mathrm{FEV}_{1}$ expressed as a percentage of FVC; $\mathrm{COPD}=$ Chronic Obstructive Pulmonary Disease; $\mathrm{StcO}_{2}=$ Transcutaneous oxygen-haemoglobin saturation at rest.

Table 2

Markers sputum concentrations in symptomatic smokers and COPD patients

\begin{tabular}{lccc}
\hline & Symptomatic smokers $(n=42)$ & COPD $(n=42)$ & p value \\
\hline HNP $(\mu \mathrm{g} / \mathrm{ml})$ & $1.96 \pm 2.48 ; 1.25(0.1-14)$ & $14.99 \pm 9.25 ; 16(0.25-34.5)$ & $<0.0001$ \\
NE $(\mu \mathrm{g} / \mathrm{ml})$ & $1.45 \pm 1.63 ; 0.9(0.5-8)$ & $3.37 \pm 2.41 ; 3(0.6-8)$ & $<0.0001$ \\
IL-8 $(\mathrm{ng} / \mathrm{ml})$ & $8.58 \pm 4.43 ; 8.05(1.9-21.2)$ & $16.18 \pm 3.96 ; 17.35(2-21.7)$ & $<0.0001$ \\
MMP-9 $(\mathrm{ng} / \mathrm{ml})$ & $392.71 \pm 162.10 ; 350(99.8-700)$ & $596.31 \pm 160.16 ; 553.5(250.7-1010.8)$ & $<0.0001$ \\
\hline
\end{tabular}

Values are expressed as mean \pm Standard Deviation; median (range).

Statistical analyses were performed by using SPSS 15 software (Statistical Package for the Social Sciences, Chicago, IL, USA), CIA 2.0 (T Bryant, 2000, University of Southampton) software and R.

\section{Results}

\subsection{Patients' characteristics and sputum markers' concentrations}

We enrolled in the study 84 smokers, 42 were symptomatic smokers with no airway obstruction, 24 had mild to moderate functional impairment and 18 had severe COPD.

Baseline characteristics of the study participants are shown in Table 1.

The sputum concentrations of HNP, NE, IL-8, MMP9 were significantly higher in individuals with COPD as compared to symptomatic smokers (Table 2).

Among COPD patients, HNP and NE concentrations were higher in individuals with severe airways obstruction as compared to subjects with mild to moderate COPD (HNP: $18.78 \pm 8.31$, median 17 , range $3-32 \mu \mathrm{g} / \mathrm{ml}$ vs. $12.16 \pm 9.00$, median 12.7 , range $0.25-$ $34.5 \mu \mathrm{g} / \mathrm{ml}, p=0.017$; NE: $4.68 \pm 2.46$, median 3.5 , range $0.6-8 \mu \mathrm{g} / \mathrm{ml}$ vs. $2.40 \pm 1.91$, median 2.15 , range $0.7-8 \mu \mathrm{g} / \mathrm{ml}, p=0.02)$. No significant differences were found in IL- 8 and MMP-9 concentrations between patients with severe and mild to moderate COPD (IL-
8: $17.31 \pm 2.89$, median 18 , range $12-21.7 \mathrm{ng} / \mathrm{ml}$ vs. $15.33 \pm 4.47$, median 16.5, range $2-21 \mathrm{ng} / \mathrm{ml}, p=$ 0.133; MMP-9: $544.44 \pm 131.33$, median 547.25, range $250.7-750.8 \mathrm{ng} / \mathrm{ml}$ vs $635.21 \pm 171.16$, median 600.35 , range $349-1010.8 \mathrm{ng} / \mathrm{ml}, p=0.121$ ).

No correlations were observed between markers concentrations and cigarettes per day, years of smoking, pack/years, $\mathrm{StcO}_{2}$.

\subsection{Correlation between sputum markers and pulmonary functional impairment and evaluation of disease progression}

A significant negative correlation was observed between $\mathrm{FEV}_{1}$ and HNP (rho $=-0.566 ; p<0.01$ ), $\mathrm{NE}($ rho $=-0.519 ; p<0.01)$ and IL-8 levels (rho $=-0.665 ; p<0.01$ ) (Fig. 1, panels A-C).

A significant correlation was also observed between $\mathrm{FEV}_{1} / \mathrm{FVC}$ and HNP (rho $=-0.665 ; p<0.01$ ), $\mathrm{NE}(\mathrm{rho}=-0.482 ; p<0.01)$ and IL-8 levels (rho $=-0.529 ; p<0.01$ ) (Fig. 1, panels D-F).

No correlations were found between both $\mathrm{FEV}_{1}$ and $\mathrm{FEV}_{1} / \mathrm{FVC}$ and MMP-9.

Sixty-six individuals underwent the 2 years PFTs assessment. The average interval between baseline evaluation and follow-up was 22 months $( \pm 2)$. A negative correlation was observed between sputum NE levels measured at enrolment and the annual decline in FEV1\% predicted (rho $=-0.25, p=0.04)$ (Fig. 2). 


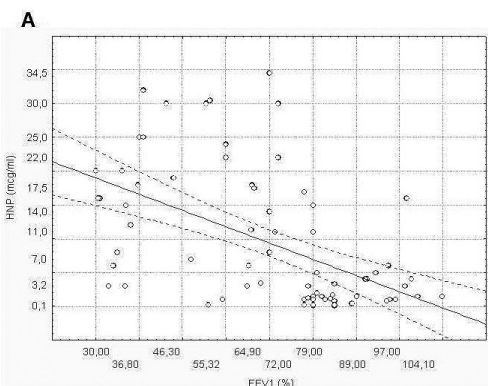

D

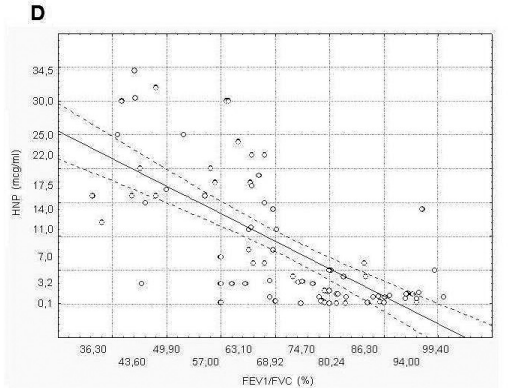

B

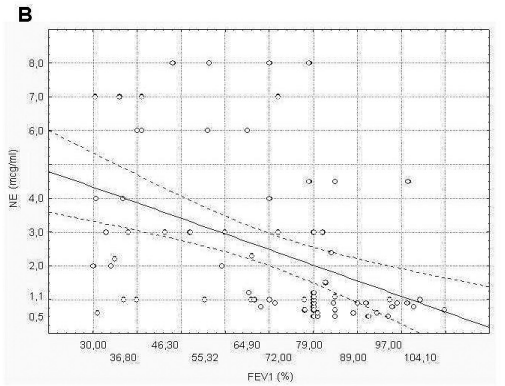

E

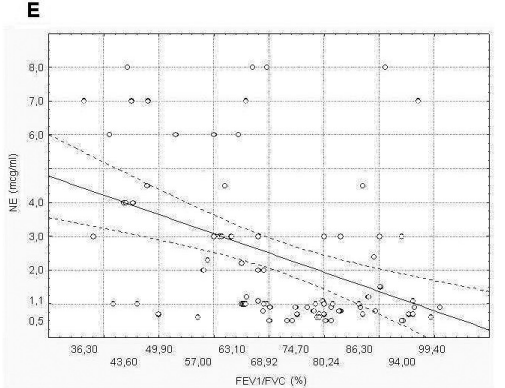

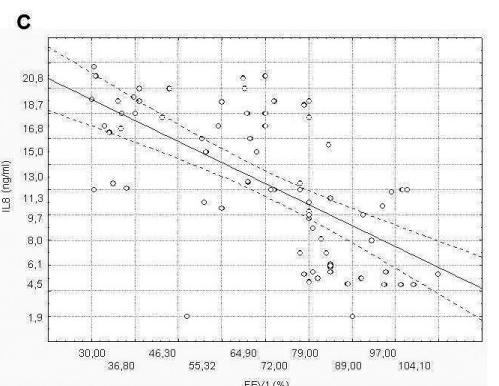

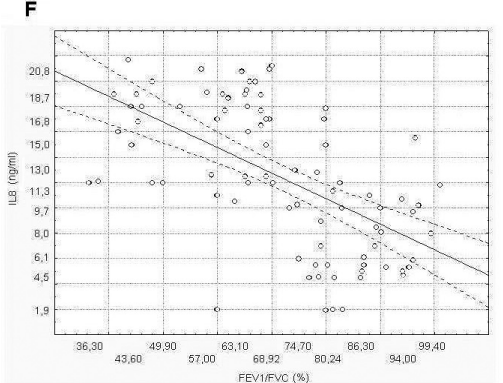

Fig. 1. Correlation between FEV 1 and HNP, NE and IL-8 concentrations (Panel A, Panel B, Panel C, respectively), and between FEV 1 /FVC and HNP, NE and IL-8 concentrations (Panel D, Panel E, Panel F, respectively).

\subsection{Diagnostic accuracy of evaluated inflammatory markers}

The ROC analysis results for symptomatic smokers and COPD patients are presented in Fig. 3 (panel A).

The AUC for HNP was 0.92 (95\% CI: 0.862-0.981); the AUC for IL-8 was 0.89 (95\% CI: $0.82-0.97)$; the AUCs for MMP-9 and NE were 0.81 (95\% CI: 0.710.90). Although the AUC for HNP was the largest, there were no significant differences between AUCs.

In addition, logistic regression was used to test the discriminatory effect of variables considered together; the linear prediction score, based on the combination of three markers (by means the following formula: $0.255 * \mathrm{HNP}+0.36 * \mathrm{IL}-8+0.01 * \mathrm{MMP}-9)$ yielded an AUC of 0.981 (95\% CI: 0.98-1.00) (Fig. 3, panel B).

Positive and negative likelihood ratios (LR+ and LR-), sensitivity and specificity calculated for each variable and for the three markers combined together are shown in Table 3.

The 3 markers combined together yielded a sensitivity significantly higher as compared to those obtained by MMP-9 and NE ( $p=0.01$ and $p=0.004$ respectively). The specificity observed using the panel of markers was significantly superior to those obtained by using the single molecules (vs. HNP $p=0.007$; vs. MMP-9 $p=0.003$; vs. IL-8 $p=0.02$ and vs. NE $p=$ 0.004).

\subsection{Effect of smoking cessation on airway inflammation in sputum}

Sputum samples from 26 subjects who quitted smoking (11 with and 15 without COPD) were obtained 6 months after smoking cessation.

No differences were found between HNP, NE, IL-8 and MMP-9 sputum levels at baseline evaluation and after 6 months of smoking withdrawal (HNP: $7.05 \pm$ 8.22, median 3.00, range $0.1-24 \mu \mathrm{g} / \mathrm{ml}$ vs. $7.44 \pm 9.03$, median 2.20 , range $0.1-24.2 \mu \mathrm{g} / \mathrm{ml}, p=0.827$; NE: $1.81 \pm 2.07$, median 0.90 , range $0.5-8 \mu \mathrm{g} / \mathrm{ml}$ vs. 1.80 \pm 2.05 , median 0.90 , range $0.3-8.0 \mu \mathrm{g} / \mathrm{ml}, p=0.909$; IL-8: $11.75 \pm 5.86$, median 10.90 , range $2-21.0 \mathrm{ng} / \mathrm{ml}$ vs. $11.08 \pm 7.60$, median 7.40 , range $1-29.5 \mathrm{ng} / \mathrm{ml}$, $p=0.461$; MMP-9: $440.38 \pm 204.34$, median 448.15, range $124.2-1010.8 \mathrm{ng} / \mathrm{ml}$ vs. $448.08 \pm 242.42$, median 402.7; range $131-1000 \mathrm{ng} / \mathrm{ml}, p=0.974)$.

The sputum concentrations of HNP, NE, IL-8 and MMP-9 remained significantly higher in individuals with COPD as compared to symptomatic smokers (HNP: $16.09 \pm 7.67$, median 18.00 , range $1.9-$ $24.2 \mu \mathrm{g} / \mathrm{ml}$ vs. $1.10 \pm 1.29$, median 0.50 , range $0.1-$ $4.0 \mu \mathrm{g} / \mathrm{ml}, p<0.0001$; NE: $2.92 \pm 2.63$, median 2.50, range $0.4-8 \mu \mathrm{g} / \mathrm{ml}$ vs. $0.98 \pm 0.92$, median 0.70 , range $0.3-4.0 \mu \mathrm{g} / \mathrm{ml}, p=0.01$; IL-8: $15.27 \pm 8.02$, median 15.3 , range $6-29.5 \mathrm{ng} / \mathrm{ml}$ vs. $8.00 \pm 5.76$, median 6.7, range 1-20.1 ng/ml, $p=0.01$; MMP-9: $622.8 \pm$ 
Table 3

Likelihood ratios, Sensitivity and Specificity of inflammatory markers

\begin{tabular}{lcccc}
\hline & LR+ & LR- & Sensitivity & Specificity \\
\hline HNP & $3.55(2.12-5.93)$ & $0.10(0.03-0.29)$ & $0.93(0.81-0.98)$ & $0.74(0.59-0.85)$ \\
MMP-9 & $2.46(1.52-3.99)$ & $0.34(0.19-0.61)$ & $0.76(0.61-0.87)$ & $0.69(0.54-0.81)$ \\
IL-8 & $4.33(2.41-7.78)$ & $0.09(0.03-0.27)$ & $0.93(0.81-0.98)$ & $0.79(0.64-0.88)$ \\
NE & $2.5(1.49-4.18)$ & $0.4(0.24-0.67)$ & $0.71(0.56-0.83)$ & $0.71(0.56-0.83)$ \\
HNP+IL-8+MMP-9 & $20(5.16-77.47)$ & $0.05(0.01-0.19)$ & $0.95(0.84-0.99)$ & $0.95(0.84-0.99)$ \\
\hline
\end{tabular}

LR+: Positive likelihood ratio; LR-: Negative likelihood ratio.

In parenthesis the $95 \% \mathrm{CI}$.

Cut-off values: HNP $2.5 \mu \mathrm{g} / \mathrm{ml}$; MMP-9 $475 \mathrm{ng} / \mathrm{ml}$; IL-8 $11.5 \mathrm{ng} / \mathrm{ml}$; NE 1.05; HNP+IL-8+MMP-9 10.77 .

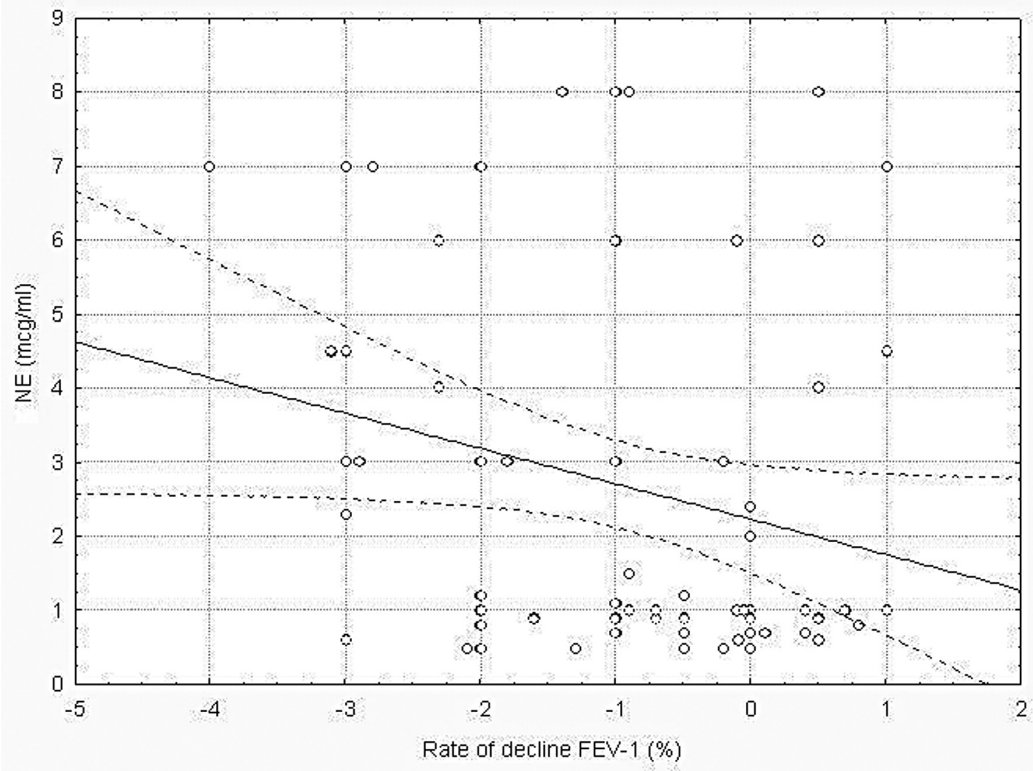

Fig. 2. Correlation between NE concentrations at baseline and $\mathrm{FEV}_{1}$ rate of decline percentage.

A

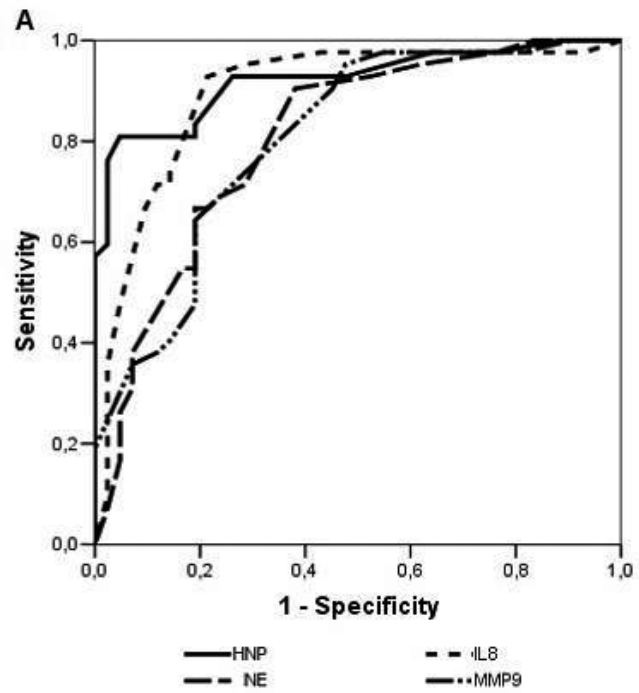

B

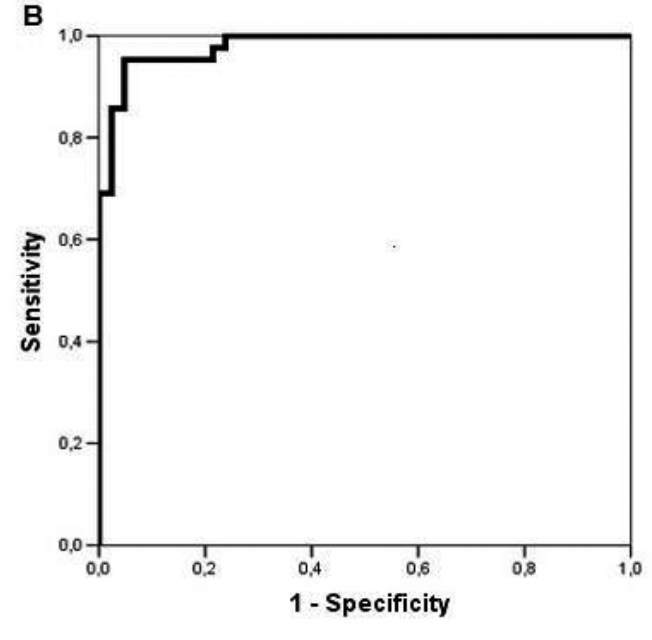

Fig. 3. Panel A. ROC curve of four inflammatory markers. Panel B. ROC curve for HNP, IL-8, MMP-9 in combined prediction model. 
244.1 , median 600 , range $145.5-1000 \mathrm{ng} / \mathrm{ml}$ vs 313.33 \pm 138.65 , median 300.0, range $131-599.8 \mathrm{ng} / \mathrm{ml}, p=$ $0.002)$.

\section{Discussion}

Smoking is considered a major risk for the development of COPD, however, only a fraction of smokers (15\%) will develop the functional and clinical manifestations of the disease [19].

Currently, after the assessment of the smoking habit and/or occupational exposures, the definition of a diagnosis of COPD requires the detection of airflow obstruction associated to a history of cough, sputum and dyspnoea [20].

Since pulmonary function tests represent the only means to identify and monitor airflow obstruction, the diagnosis and staging of COPD are largely based on $\mathrm{FEV}_{1}$ measures. Unfortunately, pulmonary function measurements are of limited practical usefulness in predicting long-term health changes, because long follow up periods are necessary to detect relevant modifications of the patient status [20].

COPD is therefore a substantially underestimated disorder, with a diagnosis typically delayed until the airway obstruction appears and the condition is advanced, at a degree where it is no longer reversible. So it becomes essential to identify surrogate outcome measures of the clinical and pathophysiological abnormalities in COPD, capable of predicting long-term responses.

Several inflammatory and anti-inflammatory molecules $[2,4,9,10,16,18,21-34]$ have been evaluated, with the intent to assess whether their levels, in sputum and/or bronchoalveolar lavage (BAL) fluid, are increased in smokers and COPD patients, and correlate with the degree of airflow obstruction but, despite all the spent efforts, established screening markers and valuable molecules, to monitor disease progression in COPD, are still lacking.

In the present study we selected four pro-inflammatory molecules, major products of neutrophils and alveolar macrophages, which interact in the smokingrelated lung inflammation leading to COPD [7].

Nearly absent in the normal lung, HNP have been found increased in airways of patients with neutrophil related inflammatory lung diseases [35-38].

HNP are small molecular weight peptides abundant in neutrophils, which may be released upon activation in the extracellular environment [39]. In a previous report we found increased levels of HNP in BAL from smokers [40], but no correlation analysis between HNP levels and functional impairment was performed.

$\mathrm{NE}$, released from activated neutrophils during inflammation, hydrolyzes proteins of the extracellular matrix with elastin as a major target [41].

HNP and NE interact to enhance each others' deleterious effects. HNP may contribute to neutrophils recruitment by stimulating, together with NE, alveolar macrophage's release of chemotactic molecules (e.g., Leukotriene B4, and IL-8) [36] and may exacerbate the imbalance between $\alpha 1$-antitrypsin ( $\alpha 1$-AT) and neutrophil elastase by inactivating $\alpha 1$-AT [42].

IL-8, secreted by alveolar macrophages, recruits neutrophils, which in turn release HNP and NE [43].

MMP-9 is the major elastolytic MMP produced by macrophages and may contribute to lung injury by activating HNP [44]. Furthermore, NE, by inactivating Tissue Inhibitors of Metalloproteinases (TIMPs) maintains MMPs' activity [45].

Herein we report that sputum samples from patients with COPD contain significantly higher levels of HNP, NE, IL-8 and MMP-9 as compared to symptomatic smokers, and that, among COPD patients, HNP and NE concentrations are increased in individuals with severe airways obstruction as compared to subjects with mild to moderate COPD. We also demonstrate that these molecules, tested singularly or combined, are able to discriminate between subjects with and without pulmonary functional impairment.

In addition sputum HNP, NE and IL-8 concentrations correlate with the degree of airway obstruction, based on $\mathrm{FEV}_{1}$ and $\mathrm{FEV}_{1} / \mathrm{FVC}$ measures, and $\mathrm{NE}$ baseline concentrations are associated with annual decline in FEV1\% predicted during a two year follow-up period.

Therefore our findings suggest that these molecules may have a role in monitoring lung inflammation and may be connected with airway obstruction and disease progression. Our report, while confirming previous data showing a correlation between NE and IL-8 sputum levels and pulmonary function (in studies with similar or smaller populations) $[2,4,9,10,16,21-26]$, indicate, for the first time, that also HNP may be considered as a new marker of chronic inflammation and pulmonary functional impairment during COPD.

A biomarker, by definition, should possess sufficient discriminatory power, in terms of sensitivity and specificity, to reflect disease state. In order to analyse the markers ability to differentiate smokers with and without COPD, we performed a receiver operating characteristic (ROC) analysis. As shown by the ROC curve, all the selected markers own a significant diagnostic 
accuracy to discriminate between symptomatic smokers and patients with pulmonary functional impairment; interestingly the AUC analysis indicate that HNP has the highest diagnostic ability to distinguish the two groups of subjects, and may suggest its role as a major neutrophil-derived marker to monitor the disease progression. A promising and tantalising approach to obtain the maximum classification accuracy would be to use a panel of molecules combined together; in this regard our attempt resulted in a significantly enhanced diagnostic accuracy as compared to each single marker. Along with other independent studies that analyze the possibility to associate discriminant power of more variables $[46,47]$, we believe that our data should be considered as an additional attractive effort to optimize the biomarkers performance in monitoring the COPD clinical course.

Importantly, we also tested our biomarkers ability to predict functional impairment: we found a correlation between NE sputum baseline levels and the annual decline in predicted FEV1\%, in line with previous results obtained using BAL samples [48]. Therefore our results suggest that sputum analysis, a non invasive procedure well tolerated by patients, could replace invasive approaches for studying respiratory tract inflammation.

Moreover our findings, together with the high discriminative accuracy demonstrated by HNP, and with the significantly higher levels of HNP and NE observed in severe COPD, may represent another piece of evidence of neutrophil-associated inflammation in COPD pathogenesis and progression.

Finally, with the aim to identify new molecules that could trace the effect of smoking cessation on airway inflammation in smokers with and without COPD, we organized a smoking cessation program and designed a longitudinal study to test whether smoking withdrawal may reduce HNP and NE concentrations, as an effect of the decreased inflammatory status.

According with previous reports [10,49], we found no decrease of IL-8 and MMP-9 levels in sputum samples of smokers who successfully quitted smoking and, moreover, no reduction in HNP and NE concentrations was observed.

We are aware that the explanation for this finding may not be univocal. It may reflect the persistence of lung inflammation after smoking cessation, or it may mirror a healing of defence mechanisms after recovering from the deleterious effects of smoking.

In conclusion, our results indicate that HNP may be considered as a novel useful marker of airway inflammation and obstruction during smoking, and sug- gest that the use of a panel of markers may optimize the diagnostic accuracy in discriminating symptomatic smokers from COPD patients. With the limitation of a mono-institutional study, we believe that our observations may prompt further investigations to validate the potential ability of sputum biomarkers to monitor the disease in patients with COPD, and to predict which subgroup of smoking subjects could be at risk to develop functional impairment.

\section{References}

[1] K.F. Rabe, S. Hurd, A. Anzueto, P.J. Barnes, S.A. Buist, P. Calverley, Y. Fukuchi, C. Jenkins, R. Rodriguez-Roisin, C. van Weel and J. Zielinski, Global Initiative for Chronic Obstructive Lung Disease: Global strategy for the diagnosis, management, and prevention of chronic obstructive pulmonary disease: GOLD executive summary, Am J Respir Crit Care Med 176 (2007), 532-555.

[2] V. Kim, T.J. Rogers and G.J. Criner, New concepts in the pathobiology of chronic obstructive pulmonary disease, Proc Am Thorac Soc 5 (2008), 478-485.

[3] J.C. Hogg, P.T. Macklem and W.M. Thurlbeck, Site and nature of airway obstruction in chronic obstructive lung disease, $N$ Engl J Med 278 (1968), 1355-1360.

[4] C. Yamamoto, T. Yoneda, M. Yoshikawa, A. Fu, T. Tokuyama, K. Tsukaguchi and N. Narita, Airway inflammation in COPD assessed by sputum levels of interleukin-8, Chest 112 (1997), 505-510.

[5] B. Burrows, J.W. Bloom, G.A. Traver and M.G. Cline, The course and prognosis of different forms of chronic airways obstruction in a sample from the general population, $N$ Engl J Med 317 (1987), 1309-1314.

[6] P.J. Barnes, B. Chowdhury, S.A. Kharitonov, H. Magnussen, C.P. Page, D. Postma and M. Saetta, Pulmonary biomarkers in chronic obstructive pulmonary disease, Am J Respir Crit Care Med 174 (2006), 6-14.

[7] G.W. Hunninghake and R.G. Crystal, Cigarette smoking and lung destruction. Accumulation of neutrophils in the lung of cigarette smokers, Am Rev Respir Dis 128 (1983), 833-838.

[8] F. Garcia-Rio, M. Miravitlles, J.B. Soriano, L. Muñoz, E. Duran-Tauleria, G. Sánchez, V. Sobradillo and J. Ancochea, EPI-SCAN Steering Committee, Systemic inflammation in chronic obstructive pulmonary disease: a population-based study, Respir Res 11 (2010), 63.

[9] B.W.M. Willemse, N.H.T. ten Hacken, B. Rutgers, I.G.A.T. Lesman-Leegte, D.S. Postma and W. Timens, Effect of 1year smoking cessation on airway inflammation in COPD and asymptomatic smokers, Eur Respir J 26 (2005), 835-845.

[10] B.W. Willemse, N.H. ten Hacken, B. Rutgers, D.S. Postma and W. Timens, Association of current smoking with airway inflammation in chronic obstructive pulmonary disease and asymptomatic smokers, Respir Res 6 (2005), 38.

[11] P.H. Quanjier, G.J. Tammeling, J.E. Cotes, O.F. Pederson, R. Peslin and J.C. Yerault, Lung volumes and forced ventilatory flows. Report Working Party Standardization of Lung Function Test, European Community for Steal and Coal. Official Statement of the European Respiratory Society, Eur Resp J Suppl 16 (1993), 5-40. 
[12] A. Efthimiadis, A. Spanevello, Q. Hamid, M.M. Kelly, M. Linden, R. Louis, M.M. Pizzichini, E. Pizzichini, C. Ronchi, F. Van Overvel and R. Djukanović, Methods of sputum processing for cell counts, immunocytochemistry and in situ hybridisation, Eur Respir J Suppl 37 (2002), 19s-23s.

[13] M.M. Kelly, V. Keatings, R. Leigh, C. Peterson, J. Shute, P. Venge and R. Djukanović, Analysis of fluid-phase mediators, Eur Respir J Suppl 37 (2002), 24s-39s.

[14] M.L. Batoli, E. Bacci, S. Carnevali, S. Cianchetti, F.L. Dente, A. Di Franco, D. Giannini, M. Taccola, B. Vagaggini and P. Paggiaro, Quality evaluation of samples obtained by spontaneous or induced sputum: comparison between two methods of processing and relationship with clinicl and functional findings, $J$ Asthma 39 (2002), 479-486.

[15] D. Górecka, M. Bednarek, A. Nowinski, E. Puscinska, A. Goljan-Geremek and J. Zielinski, Diagnosis of airflow limitation combined with smoking cessation advice increases stopsmoking rate, Chest 123 (2003), 1916-1923.

[16] A.M. Vignola, A. Bonanno, A. Mirabella, L. Riccobono, F. Mirabella, M. Profita, V. Bellia, J. Bousquet and G. Bonsignore, Increased levels of elastase and alpha1-antitrypsin in sputum of asthmatic patients, Am J Respir Crit Care Med 157 (1998), 505-511.

[17] B. Aviles, J. Belda, G. Margarit, J. Bellido-Casado, C. Martínez-Brú and P. Casan, Markers of airway remodeling in induced sputum from healthy smokers, Arch Broncopneumol 42 (2006), 235-240

[18] K.M. Beeh, J. Beier, O. Kornmann and R. Buhl, Sputum matrix metalloproteinase- 9 , tissue inhibitor of metalloprotinease1 , and their molar ratio in patients with chronic obstructive pulmonary disease, idiopathic pulmonary fibrosis and healthy subjects, Respir Med 97 (2003), 634-639.

[19] E.G. Tzorzaki, M. Tsoumakidou, D. Makris and N.M. Siafakas, Laboratory markers for COPD in "susceptible" smokers, Clin Chim Acta 364 (2005), 124-138.

[20] M. Dahl and B.G. Nordestgaard, Markers of early disease and prognosis in COPD, Int J Chron Obstruct Pulmon Dis 4 (2009), 157-167.

[21] T.S. Lapperre, L.N. Willems, W. Timens, K.F. Rabe, P.S. Hiemstra, D.S. Postma and P.J. Sterk, Small airways dysfunction and neutrophilic inflammation in bronchial biopsies and BAL in COPD, Chest 131 (2007), 53-59.

[22] A.M. Sadowska, F.J. van Overveld, D. Górecka, A. Zdral, M. Filewska, U.A. Demkow, C. Luyten, E. Saenen, J. Zielinski and W.A. De Backer, The interrelationship between markers of inflammation and oxidative stress in chronic obstructive pulmonary disease: modulation by inhaled steroids and antioxidant, Respir Med 99 (2005), 241-249.

[23] I.S. Woolhouse, D.L. Bayley and R.A. Stockley, Sputum chemotactic activity in chronic obstructive pulmonary disease: effect of alpha1-antitrypsin deficiency and the role of leukotriene B4 and interleukin 8, Thorax 57 (2002), 709-714.

[24] A. Pesci, B. Balbi, M. Majori, G. Cacciani, S. Bertacco, P. Alciato and C.F. Donner, Inflammatory cells and mediators in bronchial lavage of patients with chronic obstructive pulmonary disease, Eur Respir J 12 (1998), 380-386.

[25] S.S. Hacievliyagil, H. Gunen, L.C. Mutlu, A.B. Karabulut and I. Temel, Association between cytokines in induced sputum and severity of chronic obstructive pulmonary disease, Respir Med 100 (2006), 846-854.

[26] V.M. Keatings P.D. Collins, D.M. Scott and P.J. Barnes, Differences in interleukin-8 and tumor necrosis factor-alpha in induced sputum from patients with chronic obstructive pul- monary disease or asthma, Am J Respir Crit Care Med $\mathbf{1 5 3}$ (1996), 530-534.

27] K. Andelid, B. Bake, S. Rak, A. Lindén, A. Rosengren and A. Ekberg-Jansson, Myeloperoxidase as a marker of increasing systemic inflammation in smokers without severe airway symptoms, Respir Med 101 (2007), 888-895.

[28] Q.Y. Li, S.G. Huang, H.Y. Wan, H.C. Wu, T. Zhou, M. Li and W.W. Deng, Effect of smoking cessation on airway inflammation of rats with chronic bronchitis, Chin Med J 120 (2007), 1511-1516.

[29] A. Barczyk, E. Sozañska, M. Trzaska and W. Pierzchala, Decreased levels of myeloperoxidase in induced sputum of patients with COPD after treatment with oral glucocorticoids, Chest 126 (2004), 389-393.

[30] S. Takanashi, Y. Hasegawa, Y. Kanehira, K. Yamamoto, K. Fujimoto, K. Satoh and K. Okamura, Interleukin-10 level in sputum is reduced in bronchial asthma, COPD and in smokers, Eur Respir J 14 (1999), 309-314.

[31] J.H.J. Vernooy, J.H.N. Lindeman, J.A. Jacobs, R. Hanemaaijer and E.F.M. Wouters, Increased activity of matrix metalloproteinase- 8 and matrix metalloproteinase- 9 in induced sputum from patients with COPD, Chest 126 (2004), 1802-1810.

[32] S.V. Culpitt, D.F. Rogers, S.L. Traves, P.J. Barnes and L.E. Donnelly, Sputum matrix metalloproteases: comparison between chronic obstructive pulmonary disease and asthma, Respir Med 99 (2005), 703-710.

[33] P.F. Mercer, J.K. Shute, A. Bhowmik, G.C. Donaldson, J.A. Wedzicha and J.A. Warner, MMP-9, TIMP-1 and inflammatory cells in sputum from COPD patients during exacerbation, Respir Res 6 (2005), 151.

[34] G.C. Donaldson, T.A. Seemungal, I.S. Patel, A. Bhowmik, T.M. Wilkinson, J.R. Hurst, P.K. Maccallum and J.A. Wedzicha, Airway and systemic inflammation and decline in lung function in patients with COPD, Chest 128 (2005), 19952004.

[35] L.B. Soong, T. Ganz, A. Ellison and G.H. Caughey, Purification and characterization of defensins from cystic fibrosis sputum, Inflamm Res 46 (1997), 98-102.

[36] L.T. Spencer, G. Paone, P.M. Krein, F.N. Rouhani, J. RiveraNieves and M.L. Brantly, Role of human neutrophil peptides in lung inflammation associated with $\alpha 1$ - antitrypsin deficiency, Am J Physiol Lung Cell Mol Physiol 286 (2004), L514-L520.

[37] J. Ashitani, H. Mukae, H. Ihiboshi, H. Taniguchi, H. Mashimoto, M. Nakazato and S. Matsukura, Defensins in plasma and in bronchoalveolar lavage fluid from patients with acute respiratory distress syndrome, Nihon Kyobu Shikkan Gakkai Zasshi 34 (1996), 1349-1353.

[38] S. Van Wetering, P.J. Sterk, K.F. Rabe and P.S. Hiemstra, Defensins: key players or bystanders in infection, injury, and repair in the lung?, J Allergy Clin Immunol 104 (1999), 11311138.

[39] T. Ganz, Extracellular release of antimicrobial defensins by human polymorphonuclear leukocytes, Infect Immun $\mathbf{5 5}$ (1987), 568-571.

[40] G. Paone, A. Wada, L.A. Stevens, A. Matin, T. Hirayama, R.L. Levine and J. Moss, ADP ribosylation of human neutrophil peptide-1 regulates its biological properties, Proc Natl Acad Sci USA 99 (2002), 8231-8235.

[41] P.S. Hiemstra, S. van Wetering and J. Stolk, Neutrophil serine proteinases and defensins in chronic obstructive pulmonary disease. Effects on pulmonary epithelium, Eur Respir J 12 (1998), 1200-1208. 
[42] A.V. Panyutich, P.S. Hiemstra, S. van Wetering and T. Ganz, Human neutrophil defensin and serpins form complexes and inactivate each other, Am J Respir Cell Mol Biol 12 (1995), 351-357.

[43] S.L. Kunkel, T. Standiford, K. Kasahara and R.M. Strieter, Interleukin-8 (IL-8): the major neutrophil chemotactic factor in the lung, Exp Lung Res 17 (1991), 17-23.

[44] P.T.G. Elkington and J.S. Friedland, Matrix metalloproteinases in destructive pulmonary pathology, Thorax 61 (2006), 259266.

[45] Y. Okada, S. Watanabe, I. Nakanishi, J. Kishi, T. Hayakawa, W. Watorek, J. Travis and H. Nagase, Inactivation of tissue inhibitor of metalloproteinases by neutrophil elastase and other serine proteinases. FEBS Lett 229 (1988), 157-160.

[46] G. Paone, G. De Angelis, L. Portalone, S. Greco, S. Giosué, A. Taglienti, A. Bisetti and F. Ameglio, Validation of an algorithm able to differentiate small-cell lung cancer (SCLC) from non- small-cell lung cancer (NSCLC) patients by means of a tumour marker panel: analysis of the errors, Br J Cancer 75 (1997), 448-450.

[47] P. Beirne, P. Pantelidis, P. Charles, A.U. Wells, D.J. Abraham, C.P. Denton, K.I. Welsh, P.L. Shah, R.M. du Bois and P. Kelleher, Multiplex immune serum biomarker profiling in sarcoidosis and systemic sclerosis, Eur Respir J 34 (2009), 1376-1382.

[48] F. Rouhani, G. Paone, N.K. Smith, P. Krein, P. Barnes and M.L. Brantly, Lung neutrophil burden correlates with increased proinflammatory cytokines and decreased lung function in individuals with alpha(1)-antitrypsin deficiency, Chest 117 (2000), 250S-251S.

[49] N. Louhelainen, H. Stark, W. Mazur, P. Rytilä, R. Djukanovic and V.L. Kinnula, Elevation of sputum matrix metalloproteinase- 9 persists up to 6 months after smoking cessation: a research study, BMC Pulm Med 10 (2010), 13. 


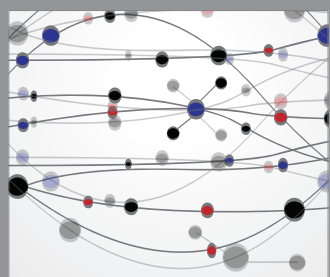

The Scientific World Journal
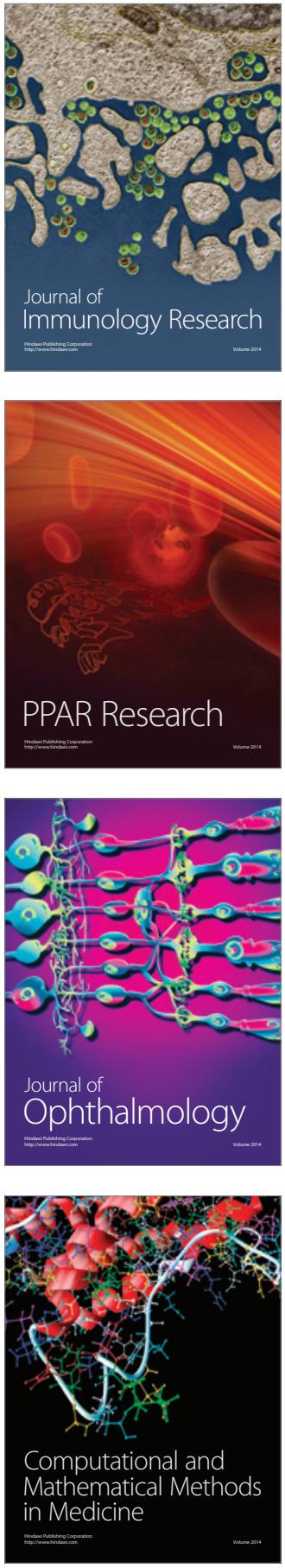

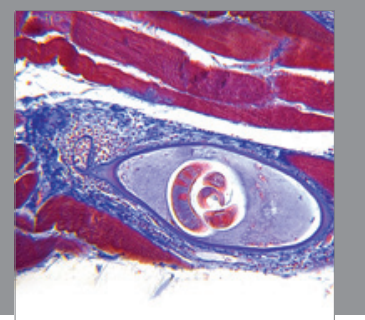

Gastroenterology

Research and Practice
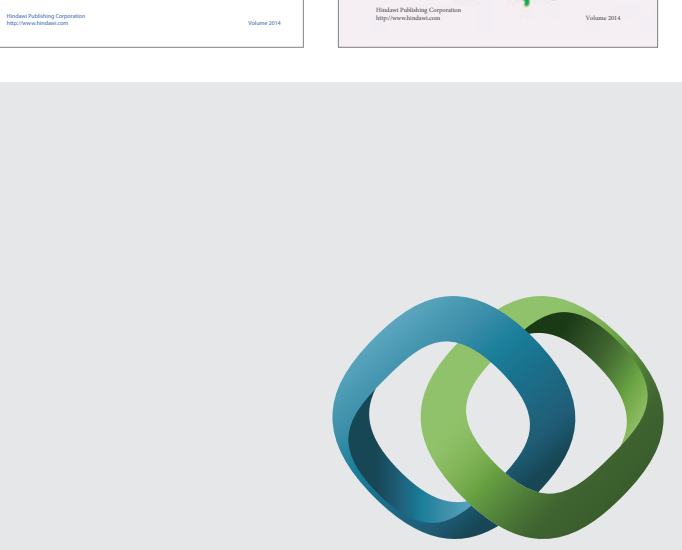

\section{Hindawi}

Submit your manuscripts at

http://www.hindawi.com
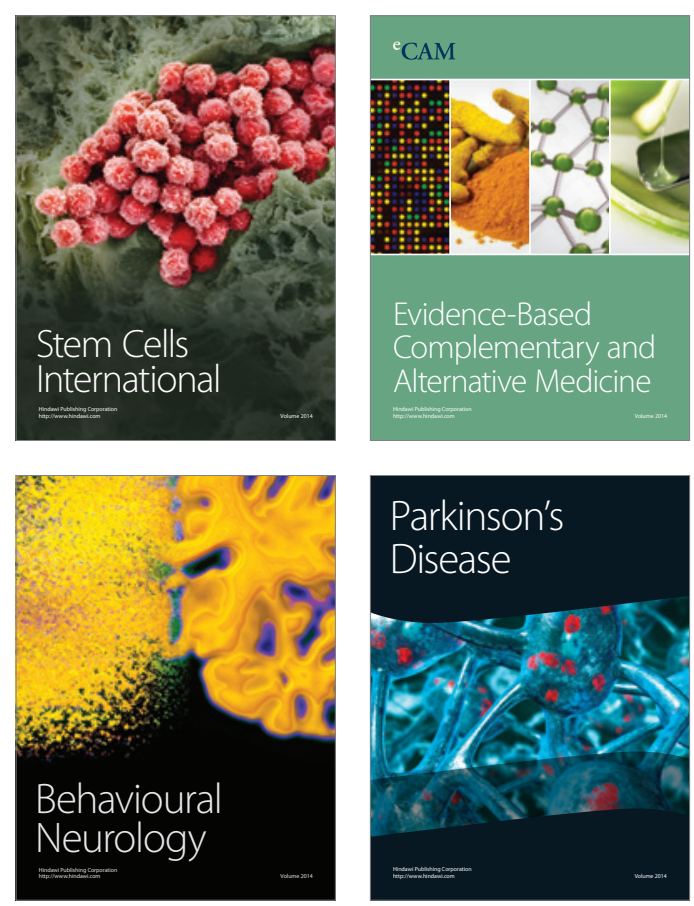

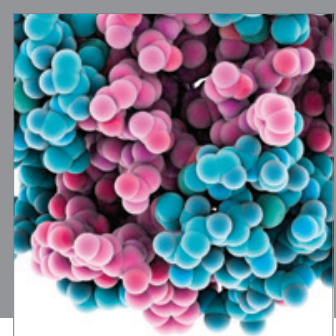

Journal of
Diabetes Research

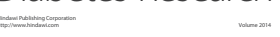

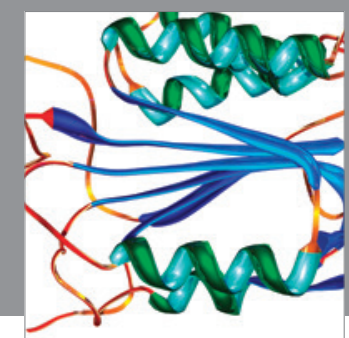

Disease Markers
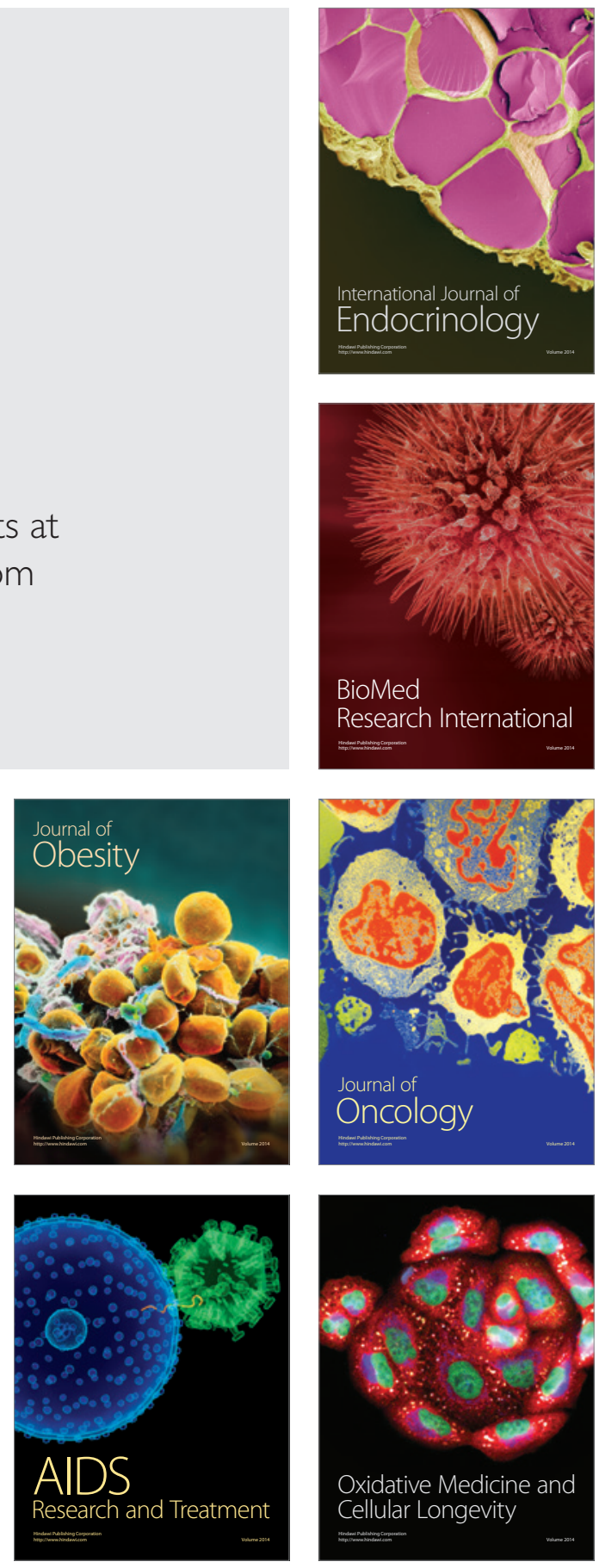